\title{
Característica produtiva e estrutural de pastos mistos de aveia e azevém manejados em quatro alturas sob lotação contínua
}

\author{
Paulo César de Faccio Carvalho ${ }^{1}$, Lemar Maciel da Rocha ${ }^{2}$, Carolina Baggio ${ }^{2}$, Stefani \\ Macari $^{2}$, Taise Robinson Kunrath ${ }^{3}$, Aníbal de Moraes ${ }^{4}$
}

\footnotetext{
${ }^{1}$ Faculdade de Agronomia/Universidade Federal do Rio Grande do Sul.

2 Programa de Pós-graduação em Zootecnia - Universidade Federal do Rio Grande do Sul.

${ }^{3}$ Bolsista de Iniciação Científica, Curso de Agronomia - Universidade Federal do Rio Grande do Sul.

${ }^{4}$ Setor de Ciências Agrárias - Universidade Federal do Paraná
}

RESUMO - Monitoraram-se variáveis relacionadas à produção e à estrutura de pastos de aveia-preta (Avena strigosa, Schreb) e azevém (Lolium multiflorum, Lam) manejados em quatro alturas (10, 20, 30 e $40 \mathrm{~cm}$ ), em pastejo contínuo com lotação variável (put and take). Utilizaram-se novilhos de corte mestiços de aproximadamente 10 meses de idade com peso médio inicial de $190 \mathrm{~kg}$, em delineamento de blocos completos casualizados com três repetições. Investigou-se o tipo de distribuição das frequências de altura em seis datas, bem como o potencial de predição da massa seca de forragem por meio da altura do pasto. A massa de forragem aumentou de forma linear de acordo com a altura do pasto: cada $1 \mathrm{~cm}$ de aumento na altura acima de $10 \mathrm{~cm}$ correspondeu a um acréscimo de cerca de $107 \mathrm{~kg}$ de MS/ha na massa de forragem. Não houve efeito da altura do pasto na taxa de acúmulo (55,8 kg de MS/ha.dia) nem na produção total de matéria seca (8.210 kg de MS/ha). A distribuição das frequências ajustou ao modelo normal em apenas uma das 96 séries analisadas. A distribuição tipo Gamma fo a que mais frequentemente se ajustou aos dados de altura do pasto, porém, uma vez iniciado o pastejo, a heterogeneidade no pasto foi tão alta que a distribuição das alturas não se ajustou a nenhum dos modelos estudados. É possível estimar a massa seca de forragem existente no pasto por meio de sua altura média, assim, sugere-se estabelecer alturas variáveis ao longo do ciclo de pastejo, com o intuito de se administrar a heterogeneidade causada pelo animal.

Palavras-chave: altura do pasto, Avena strigosa, estrutura do pasto, Lolium multiflorum, manejo do pastejo

\section{Structural and productive characteristic of oat and ryegrass mixed pastures managed in four intensities with variable stocking rate}

\begin{abstract}
It was monitored variables related to production and structure of oat (Avena strigosa Schreb) and ryegrass (Lolium multiflorum Lam) pastures managed at four sward heights $(10,20,30$, and $40 \mathrm{~cm}$ ) on continuous grazing with variable stocking (put and take). It was used crossbred beef steers at approximately 10 months of age and an average initial weight $190 \mathrm{~kg}$ in a complete random block design with three replicates. The type of sward height distribution in six different sample dates as well as the forage dry mass prediction through sward heights were investigated. Forage mass linearly increased according to the sward height: for each $1-\mathrm{cm}$ increase of the height above $10 \mathrm{~cm}$, there was an approximately $107 \mathrm{~kg}$ DM/ha addition in the forage mass. There was no effect of sward height on the accumulation rate (55.8 kg DM/ha) neither on the dry matter total production $(8,210 \mathrm{~kg}$ of $\mathrm{DM} / \mathrm{ha})$. Frequency distributions fitted to the normal model in only one out of the 96 analyzed data series. Gamma type distribution was the one that was the most frequently adjusted to sward height data, however, once grazing was started, pasture heterogeneity was so high that height distribution did not fit any of the investigated models It is possible to estimate forage dry mass on the pasture by its average height so it is suggested to establish variable heights over the grazing cycle aiming to manage the heterogeneity caused by the animal.
\end{abstract}

Key Words: Avena strigosa, grazing management, Lolium multiflorum, sward height, sward structure

\section{Introdução}

Plantas forrageiras anuais de inverno são muito utilizadas no Rio Grande do Sul. Estas se constituem em importante fonte de alimento para milhares de herbívoros domésticos. Sendo utilizadas como pastagens, são reconhecidas por proporcionarem elevada produção animal. Ganhos de peso diários superiores a 1 kg/animal e produções de leite superiores a 20 l/animal são frequentemente encontrados na literatura (Silva \& Carvalho, 2005).

Apesar de seu elevado potencial produtivo, as pastagens anuais se caracterizam por um ciclo curto de 
utilização, usualmente entre 100 e 120 dias, e por mudanças estruturais rápidas e de forte magnitude. Pontes et al. (2004) reportaram, para pastos de azevém, que massas de forragem distintas podem conter massas semelhantes de lâminas foliares. A consequência da forte variação na estrutura das pastagens anuais é a variação no desempenho dos animais. Ainda que a média do desempenho resultante de todo o período de utilização seja sempre elevada, conforme anteriormente mencionado, a variação entre o início e o final do ciclo é bastante pronunciada.

Há razões para se supor que essa diferença esteja associada não somente ao decréscimo em valor nutritivo da forragem ofertada com o passar da fenologia das espécies anuais (Aguinaga et al., 2006), mas também a mudanças estruturais do pasto que afetam o processo de busca e apreensão da forragem pelo animal em pastejo (Carvalho et al., 2001).

A consequência da heterogeneidade na estrutura do pasto é que a proposição de manejo do pastejo por meio de metas de estrutura (por exemplo, altura predeterminada de pastejo), tal qual vem sendo manejada para pastagens de clima temperado e tropical (Silva \& Carvalho, 2005), torna-se, em princípio, de menor poder preditivo, pois as estruturas não se mantêm ao longo do ciclo de utilização, problema esse que é facilmente percebido em pastagens anuais.

Com o objetivo de descrever e quantificar as mudanças estruturais de pastagens associadas de aveia e azevém durante seu ciclo de utilização, diferentes alturas de manejo foram impostas buscando criar níveis de oportunidade de seleção e, consequentemente, níveis de heterogeneidade no pasto. Investigou-se a hipótese de que a quantidade de forragem em oferta possa ser predita pela altura do pasto, e que quanto maior a meta de altura de manejo do pasto, maior a ocorrência de áreas com vegetação alta e baixa, ou seja, maior a heterogeneidade do pasto oferecido ao animal.

\section{Material e Métodos}

O experimento foi conduzido na Fazenda do Espinilho, pertencente à Agropecuária Cerro Coroado Ltda. e localizada no município de São Miguel das Missões, região fisiográfica do Planalto Médio do Rio Grande do Sul, distante $470 \mathrm{~km}$ de Porto Alegre (latitude $29^{\circ} 03^{\prime} 10^{\prime \prime}$ sul e longitude $53^{\circ} 50^{\prime} 44^{\prime \prime}$ oeste.

A área experimental vem sendo cultivada há treze anos sob semeadura direta de soja, no verão, e pastagem anual no inverno. O solo do local é classificado como Latossolo Vermelho Distroférrico típico, desenvolvido a partir de rochas eruptivas básicas, sendo profundo, bem drenado, com coloração vermelho-escura e textura muito argilosa
(>60\% de argila) (Embrapa, 1999). A análise de solo realizada em novembro de 2004 caracterizou a camada de $0-10 \mathrm{~cm}$ da forma seguinte: $\mathrm{pH}$ em água 5,2; Ca, $\mathrm{Mg}$ e $\mathrm{Al}$ com 5,3, 2,6 e 0,5 cmolc $\mathrm{kg}^{-1}$, respectivamente, e saturação de bases de $55 \%$. Segundo o sistema de Köppen, o clima é do tipo Cfa, subtropical úmido. O relevo configura-se ondulado a suavemente ondulado.

Em 04/05/05, a pastagem de inverno, constituída de uma mistura de aveia preta (Avena strigosa Schreb) e azevém (Lolium multiflorum Lam) foi implantada por meio de semeadura direta, utilizando-se $100 \mathrm{~kg} / \mathrm{ha}$ de aveia preta (semeadura em linhas) e $25 \mathrm{~kg} / \mathrm{ha}$ de azevém (semeadura a lanço). A adubação de base foi de $300 \mathrm{~kg} / \mathrm{ha}$ de superfosfato simples, e no dia 8/6/2005 fez-se uma aplicação do nitrogênio (N) em cobertura na dose de $45 \mathrm{~kg} / \mathrm{ha}$ na forma de ureia.

Após a fase de estabelecimento do pasto, os animais iniciaram o pastejo no dia $5 / 7 / 2005$, momento em que o pasto atingira, em média, $19 \mathrm{~cm}$ de altura e $900 \mathrm{~kg}$ de MS/ha de massa de forragem. A partir de então, quatro alturas foram impostas: 10, 20, 30 e $40 \mathrm{~cm}$, dispostos em doze piquetes (1,8 ha em média) e arranjados em delineamento de blocos completos casualizados, com três repetições. Considerou-se, portanto, o piquete como unidade experimental (Fisher, 1999). Para manter os pastos na meta desejada, utilizou-se o método de pastejo de lotação contínua com taxa de lotação variável, segundo a técnica put and take proposta por Mott \& Lucas (1952). Para tal, foram utilizados 55 novilhos de corte proveniente de cruzamento industrial, com médias de idade e de peso de 10 meses e $190 \mathrm{~kg}$, respectivamente. O uso da pastagem se estendeu até 13/11/2005, totalizando 131 dias de pastejo.

Para monitorar a altura do pasto, utilizou-se um bastão graduado (sward stick - Barthram, 1985), cujo marcador em acrílico transparente corre por uma régua, marcando a distância entre o topo da superfície do pasto (lâmina foliar mais elevada) e a superfície do solo. Os registros de altura do pasto foram realizados nos dias 3/7/2005, 5/8/2005, 8/9/2005, 29/9/2005, 29/10/2005 e 12/11/2005, totalizando seis avaliações no período de pastejo. Os pontos de amostragem foram definidos de forma aleatória, totalizando 100 leituras de altura por unidade experimental, exceção feita à primeira data, quando, em virtude da ausência de pastejo anterior, e consequentemente da uniformidade, vinte leituras por unidade experimental foram realizadas.

A taxa de acúmulo de matéria seca foi registrada a cada 30 dias aproximadamente, utilizando três gaiolas de exclusão de pastejo por unidade experimental, empregando-se a técnica do triplo emparelhamento (Moraes et al., 1990). A massa seca de forragem, dentro e fora da gaiola, foi obtida por corte com tesoura, realizado rente ao solo, numa área 
delimitada por um quadrado de $0,25 \mathrm{~m}^{2}(50 \times 50 \mathrm{~cm})$. As amostras cortadas eram colocadas em saco de papel e secas em estufa de circulação forçada de ar a uma temperatura de $65^{\circ} \mathrm{C}$ durante quatro dias. Após estarem secas, foram separadas nas frações lâmina foliar e bainha+colmo e pesadas. A taxa de acúmulo média de todo o período de uso da pastagem foi obtida pela média das taxas de acúmulo de cada subperíodo avaliado, ponderada pelo intervalo de tempo correspondente a cada subperíodo.

A massa seca de forragem foi obtida pelos mesmos cortes de fora da gaiola, aos quais se somavam outros dois cortes, obtidos de forma aleatória, totalizando cinco pontos amostrados por piquete. O procedimento de manipulação e secagem das amostras seguiu o mesmo descrito para a avaliação das taxas de acúmulo. A massa seca de forragem média de todo o período foi obtida pela média das massas secas de forragem de cada subperíodo, ponderada pelo intervalo de tempo respectivo. Em todas as amostras colhidas para determinação de massa seca de forragem foi medida a altura média do pasto no quadrado amostrado, registrando-se 10 leituras de altura antes de se proceder ao corte. O valor médio dos 10 registros foi utilizado como variável independente em modelos de regressão que procuraram relacionar a altura do pasto com a massa seca de forragem.

A produção total de MS foi calculada pelo somatório da massa seca de forragem inicial com o acúmulo de forragem de cada período de amostragem. A oferta de forragem foi obtida a partir do quociente entre o acúmulo total de matéria seca e o número de dias de utilização da pastagem, e os valores foram expressos em percentual relativo ao peso corporal dos animais.

Os dados foram submetidos à análise de variância, teste Tukey a $10 \%$ e regressão a 5\% de significância pelo procedimento GLM (General Linear Models) do programa estatístico SAS (2001) versão 6.08. A distribuição das frequências das leituras de altura do pasto foi testada pelo procedimento "Distribution Fitting” do programa estatístico Statgraphics versão Plus 4.1. Em procedimento análogo ao de Barthram et al. (2005), foram testadas quatro das possíveis distribuições teóricas normalmente estudadas em pastagens, quais sejam: Normal, Log-normal, Gamma e Weibull. Os ajustes das distribuições de altura foram testados por três diferentes tipos de testes, a saber: quiquadrado, Kolmogorov-Smirnov e Anderson-Darling.

\section{Resultados e Discussão}

As médias ponderadas das alturas obtidas pelo uso de taxa de lotação variável foram muito próximas das metas de altura previamente estipuladas (Tabela 1). Com isso, o propósito de se criar estruturas contrastantes foi plenamente atingido. A diferença estatística observada entre as médias $(\mathrm{P}<0,001)$ assegura que o manejo com taxas de lotação foi satisfatório.

A menor intensidade de pastejo foi aquela que apresentou a maior distância da altura-meta, tendo em média 36,1 cm para uma altura pretendida de $40 \mathrm{~cm}$. Considerando a definição de altura com que se trabalhou, ou seja, a altura da superfície das folhas (Barthram, 1985), observou-se uma dificuldade particular em se manter a altura desejada, pois para atingirem uma altura tão elevada, a intensidade de pastejo foi tão baixa que os perfilhos rapidamente alongaram os entrenós e floresceram precocemente. Ao se manter o pastejo em todas as alturas até o final do ciclo, observou-se que as folhas da superfície da altura de $40 \mathrm{~cm}$ eram desfolhadas e não eram repostas, uma vez que em perfilhos em estádio reprodutivo ocorre cessamento do aparecimento de novas folhas (Pontes et al., 2004). Esse fenômeno de floresci-mento precoce de espécies anuais, quando submetidas a baixas intensidades de pastejo, também foi observado por Rocha et al. (2004).

Quanto menor a altura pretendida, maior a carga animal utilizada, que, no presente experimento, variou de 315 a $1084 \mathrm{~kg}$ de peso vivo/ha $(\mathrm{P}<0,001)$ (Tabela 1$)$, com as alturas diferindo entre si. Essa relação inversa entre altura do pasto e carga animal sob lotação contínua é de se esperar, à medida que mais animais por unidade de área

Tabela 1 - Altura média de manejo, carga animal e oferta de forragem de pastos mistos de aveia e azevém manejados em quatro alturas do pasto

\begin{tabular}{|c|c|c|c|c|c|}
\hline \multirow[t]{2}{*}{ Variável } & & \multicolumn{4}{|c|}{ Altura do pasto pretendida } \\
\hline & & $10 \mathrm{~cm}$ & $20 \mathrm{~cm}$ & $30 \mathrm{~cm}$ & $40 \mathrm{~cm}$ \\
\hline \multirow[t]{2}{*}{ Altura do pasto observada $(\mathrm{cm})$} & Média & $12,1 \mathrm{a}$ & $20,9 c$ & $29,3 b$ & $36,1 \mathrm{a}$ \\
\hline & e.p. & 0,4 & 0,2 & 1,0 & 1,1 \\
\hline \multirow[t]{2}{*}{ Carga animal (kg de PV/ha) } & Média & $1084 a$ & 792b & $477 c$ & $315 a$ \\
\hline & e.p. & 92,7 & 102,0 & 45,8 & 44,6 \\
\hline \multirow[t]{2}{*}{ Oferta de forragem (\% do PV) } & Média & $6,6 c$ & $7,2 \mathrm{c}$ & $13,8 b$ & $19,1 \mathrm{a}$ \\
\hline & e.p. & 1,6 & 2,1 & 1,3 & 4,4 \\
\hline
\end{tabular}

Médias com letras minúsculas distintas na mesma coluna diferem $(\mathrm{P}<0,10)$ pelo teste Tukey. 
são necessários para manter a pastagem em alturas menores, resultado de maior consumo de forragem por unidade de área.

A oferta de forragem, a exemplo das variáveis anteriores, variou com as alturas $(\mathrm{P}=0,0003)$. A amplitude de valores observados mostra, mais uma vez, o sucesso em se criar intensidades de pastejo verdadeiramente distintas. Na altura de manejo de $10 \mathrm{~cm}$, os animais tiveram uma oferta diária média de forragem da ordem de 6,6 \% do PV, valor esse considerado baixo, pois ofertas de forragem menores que 3 a 4 vezes o potencial de consumo dos animais limitariam a ingestão dos animais (Almeida et al., 2000; Sollenberger et al., 2005). Por outro lado, no outro extremo das alturas, atingiu-se uma oferta diária de 19,1 \% do PV, muito acima da capacidade de ingestão dos animais. Nessas condições, a quantidade de matéria seca oferecida não seria limitante ao consumo dos animais. Essa intensidade de pastejo, em princípio, seria suficiente para criar condições extremas de seletividade para os animais, permitindo maior ou menor possibilidade de aparecimento de estruturas heterogêneas na pastagem.
De fato, verifica-se claramente a criação de condições heterogêneas, particularmente no início do pastejo dos animais e naqueles tratamentos com menor intensidade de pastejo (Figura 1). Na primeira data, referente ao momento em que os animais foram colocados nos piquetes, o gráfico de frequências de altura demonstra que, como era de se esperar, todas as alturas apresentaram um padrão bastante homogêneo de distribuição de alturas. Entretanto, à medida que as diferentes intensidades de pastejo começaram a ser impostas, aquelas alturas com menor intensidade de pastejo passam a apresentar maiores amplitudes de valores de frequência, indicando uma maior variação do parâmetro em questão. A exemplo dos resultados registrados por Gibb \& Ridout (1988), áreas altas e baixas de pasto foram criadas, frequentemente associadas com condições de elevada seletividade por parte do animal representando, na maioria das vezes, áreas de rejeição e de pastejo, respectivamente.

No início do pastejo, a homogeneidade nas alturas de maior intensidade de pastejo, como a altura-meta de $10 \mathrm{~cm}$, pôde ser observada pela frequência de observações de altura em torno da média. Esse fenômeno é típico de

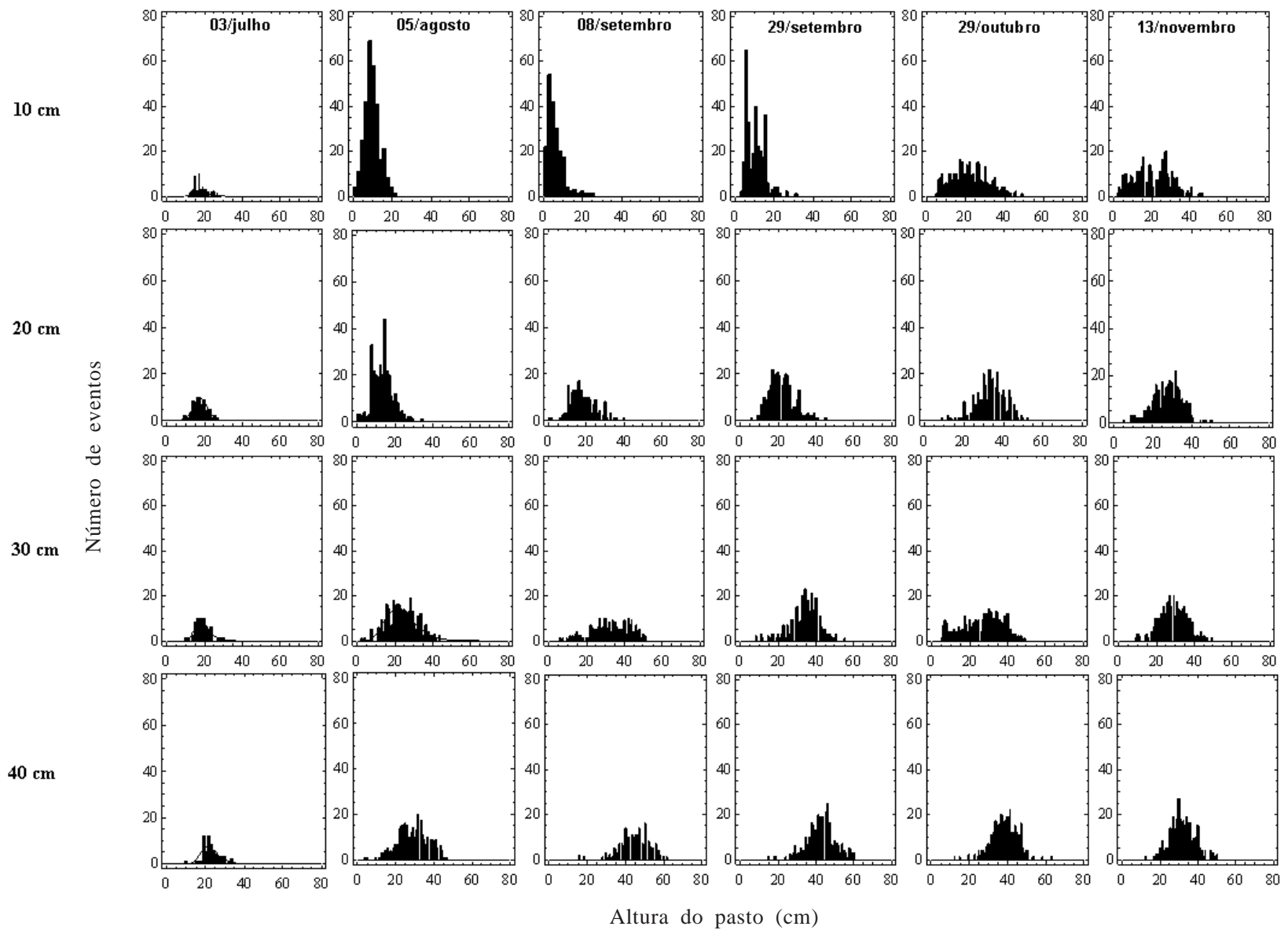

Figura 1 - Frequências de distribuição de alturas ao longo do período de pastejo em pastos mistos de aveia e azevém manejados em quatro alturas sob lotação contínua. 
condições limitantes de seletividade ao pastejo dos animais e tem impacto negativo no desempenho animal à medida que os animais se beneficiam da heterogeneidade (para situações de qualidade de forragem não contrastantes) ao pastejarem em locais cuja média seja superior à média que descreve o pasto (Carvalho et al., 2001). Garcia et al. (2005) reportaram que, quando a oferta de forragem é superior à necessidade dos animais, os animais imprimem uma pressão de pastejo variável no espaço para atingirem seus requerimentos em resposta à variabilidade que eles percebem. De forma geral, áreas baixas representam pequena quantidade de forragem de maior valor nutritivo, enquanto áreas altas representam elevada quantidade de forragem de menor valor nutritivo, estando em jogo uma relação de custo/benefício que o animal em pastejo possui ferramentas para solucionar. Segundo Garcia et al. (2005), esse comportamento de pastejo pode criar e manter áreas na pastagem que podem ser mais homogêneas que a pastagem como um todo.

A existência de áreas na pastagem com diferentes estruturas já havia sido reportada por Gibb \& Ridout (1986), que concluíram que a distribuição Normal, uma forma de interpretação da existência de heterogeneidade no pasto, não se ajustava aos dados de altura do dossel. De fato, somente na altura $20 \mathrm{~cm}$, na primeira data, ainda sem a presença dos animais, é que a distribuição de frequências pôde ser ajustada por uma distribuição do tipo Normal (Figura 1; Tabela 2).

Em todas as outras alturas, nessa mesma data, as frequências de altura foram mais bem ajustadas por distribuições do tipo Log-normal e Gamma. A distribuição tipo Gamma também se ajustou significativamente aos valores de distribuição de frequências da altura $30 \mathrm{~cm}$ na segunda data de avaliação. Porém, após a entrada dos animais, à exceção da altura de $30 \mathrm{~cm}$ na referida data, nenhuma das distribuições obteve significância estatística. Esse resultado corrobora, em parte, aqueles reportados por Barthram et al. (2005) e Sanders et al. (2003), segundo os quais a distribuição tipo Gamma seria uma das que melhor se aplicaria aos tipos de distribuição de frequências de altura do pasto normalmente observados em pastagem. Entretanto, vale ressaltar o fato de que, uma vez sob efeito do pastejo, nenhuma das distribuições testadas obteve sucesso em caracterizar as estruturas dos pastos nas diferentes alturas.

A altura $10 \mathrm{~cm}$ manteve uma estrutura mais homogênea até o final de setembro, quando então as frequências de altura observadas acima de $20 \mathrm{~cm}$ aparecem e predominam (Figura 1), como resultado da manutenção da estrutura em estádio vegetativo e com potencial de crescimento por um

Tabela 2 - Tipos teóricos de distribuição de altura em pastos mistos de aveia e azevém manejados em quatro alturas

\begin{tabular}{|c|c|c|c|c|c|c|c|c|c|c|c|}
\hline \multicolumn{2}{|c|}{ Data da amostragem } & \multirow[b]{2}{*}{ Normal } & \multicolumn{9}{|c|}{ Tipo de distribuição } \\
\hline & & & \multicolumn{2}{|l|}{ Log-normal } & \multirow{2}{*}{$\begin{array}{l}\text { Gamma } \\
\text { ura }\end{array}$} & \multirow[t]{2}{*}{ Weibull } & \multirow[t]{2}{*}{ Normal } & \multicolumn{2}{|c|}{ Log-normal } & \multirow{2}{*}{$\frac{\text { Gamma }}{\text { tura }}$} & \multirow[t]{2}{*}{ Weibull } \\
\hline & & \multicolumn{3}{|c|}{$10 \mathrm{~cm}$ de altura } & & & & \multicolumn{2}{|c|}{$20 \mathrm{~cm}$ de altura } & & \\
\hline $3 / 7 / 2005$ & Desvio-padrão & 3,31 & 3,22 & escala & 1,73 & 19,07 & 3,71 & 3,83 & escala & 1,29 & 19,12 \\
\hline \multirow[t]{2}{*}{$5 / 8 / 2005$} & Média & 9,58 & 10,54 & ajuste & 4,05 & 2,58 & 13,54 & 14,21 & ajuste & 4,82 & 2,63 \\
\hline & Desvio-padrão & 3,83 & 7,9 & escala & 0,42 & 10,69 & 5,39 & 8,57 & escala & 0,36 & 15,17 \\
\hline \multirow[t]{2}{*}{ 29/9/2005 } & Média & 10,26 & 10,3 & ajuste & 5,02 & 2,35 & 21,81 & 21,85 & ajuste & 10,73 & 3,48 \\
\hline & Desvio-padrão & 4,66 & 5,02 & escala & 0,49 & 11,62 & 6,64 & 7,03 & escala & 0,49 & 24,21 \\
\hline \multirow[t]{2}{*}{ 29/10/2005 } & Média & 22,09 & 22,38 & ajuste & 4,88 & 2,54 & 33,97 & 34,08 & ajuste & 18,72 & 5,38 \\
\hline & Desvio-padrão & 9,42 & 11,62 & escala & 0,22 & 24,92 & 7,29 & 8,49 & escala & 0,55 & 36,82 \\
\hline \multirow[t]{2}{*}{$13 / 11 / 2005$} & Média & 20,47 & 21,13 & ajuste & 3,61 & 2,26 & 27,78 & 27,97 & ajuste & 11,52 & 4,25 \\
\hline & Desvio-padrão & 9,64 & 13,74 & escala & 0,18 & 23,11 & 7,44 & 9,15 & escala & 0,42 & 30,52 \\
\hline \multirow[t]{2}{*}{$5 / 8 / 2005$} & Média & 23,7 & 23,94 & ajuste & $8,31^{*}$ & 3,38 & 29,29 & 29,51 & ajuste & 11,36 & 4,22 \\
\hline & Desvio-padrão & 7,66 & 9,38 & escala & 0,35 & 26,37 & 7,92 & 9,79 & escala & 0,39 & 32,22 \\
\hline \multirow[t]{2}{*}{$8 / 9 / 2005$} & Média & 33,03 & 33,4 & ajuste & 8,41 & 3,79 & 44,7 & 44,79 & ajuste & 30,18 & 7,1 \\
\hline & Desvio-padrão & 10,14 & 13,14 & escala & 0,26 & 36,59 & 7,49 & 8,77 & escala & 0,68 & 47,7 \\
\hline \multirow[t]{2}{*}{ 29/9/2005 } & Média & 34,36 & 34,57 & ajuste & 15,79 & 5,31 & 45,58 & 42,64 & ajuste & 29,94 & 6,47 \\
\hline & Desvio-padrão & 7,65 & 9,72 & escala & 0,46 & 37,24 & 7,39 & 8,2 & escala & 0,7 & 45,61 \\
\hline \multirow[t]{2}{*}{ 29/10/2005 } & Média & 26,41 & 27,07 & ajuste & 4,6 & 2,75 & 38,55 & 38,61 & ajuste & 28,7 & 6,25 \\
\hline & Desvio-padrão & 10,68 & 15,22 & escala & 0,17 & 29,68 & 6,81 & 7,62 & escala & 0,74 & 41,33 \\
\hline \multirow[t]{2}{*}{$13 / 11 / 2005$} & Média & 28,96 & 29,07 & ajuste & 14,79 & 4,6 & 31,9 & 31,92 & ajuste & 23,21 & 5,23 \\
\hline & Desvio-padrão & 7,07 & 8,14 & escala & 0,51 & 31,66 & 6,52 & 6,86 & escala & 0,73 & 34,55 \\
\hline
\end{tabular}

Valores seguidos por asterisco $(*)$ indicam a significância estatística $(\mathrm{P}<0,05)$ do tipo de distribuição. 
período mais prolongado de tempo. Essa substituição dos perfilhos induzidos por perfilhos em estádio vegetativo por meio de desfolhações mais intensas e frequentes é típica do emprego de intensidades de pastejo mais elevadas em gramíneas de ciclo anual (Pontes et al., 2004). Já nas maiores alturas, como as de 30 e $40 \mathrm{~cm}$, a heterogeneidade foi rapidamente criada no pasto, mas diminuiu com o avançar do ciclo de utilização. Houve uma diminuição das classes de frequência de altura mais elevada, acima de $40 \mathrm{~cm}$, como resultado do desaparecimento das folhas na estrutura do pasto. De fato, a relação lâmina/colmo+ bainha foi inferior a 1 nas alturas de 30 e $40 \mathrm{~cm}$, ao passo que, a partir do início de setembro, o mesmo fenômeno só ocorreu nas alturas de 10 e $20 \mathrm{~cm}$ no final do ciclo (Tabela 3).

Em decorrência do sucesso das intensidades de pastejo contrastantes, a massa seca de forragem foi igualmente diferente $(\mathrm{P}<0,0001)$ (Tabela 4). A magnitude registrada entre o menor e o maior valor, a exemplo do discutido para a oferta de forragem, caracteriza estruturas limitantes e não limitantes ao consumo dos animais, respectivamente.

Segundo Quadros (1999), em pastagem de inverno, massas de forragem inferiores a $1200 \mathrm{~kg} / \mathrm{ha}$ seriam limitantes ao consumo e desempenho dos animais. Para azevém perene, Bircham \& Hodgson (1983) reportaram valores de massas de forragem entre 900 e $2000 \mathrm{~kg} / \mathrm{ha} \mathrm{de}$ matéria seca para pastos entre 3 e $10 \mathrm{~cm}$ de altura.

As taxas de acúmulo de forragem não variaram com as alturas de manejo $(\mathrm{P}>0,10)$, o que pode ser explicado pelo protocolo experimental utilizado na avaliação e pelo caráter curto e dinâmico do período de utilização dos pastos. Por ocasião do início do pastejo, todas as alturas apresentavam um valor semelhante de massa seca de forragem. Isso significa que, no primeiro período de avaliação das taxas de acúmulo, as gaiolas excluem do pastejo áreas com índice de área foliar praticamente idênticos. Consequentemente, a taxa de acúmulo de forragem do primeiro dos cinco períodos

Tabela 3 - Características estruturais de pastos mistos de aveia e azevém manejados em quatro alturas e dinâmica ao longo do ciclo de utilização

\begin{tabular}{|c|c|c|c|c|c|c|c|c|c|c|c|c|}
\hline & \multicolumn{12}{|c|}{ Data de amostragem } \\
\hline & \multicolumn{2}{|c|}{$3 / 7 / 2005$} & \multicolumn{2}{|c|}{$5 / 8 / 2005$} & \multicolumn{2}{|c|}{$8 / 9 / 2005$} & \multicolumn{2}{|c|}{$29 / 9 / 2005$} & \multicolumn{2}{|c|}{ 29/10/2005 } & \multicolumn{2}{|c|}{$13 / 11 / 2005$} \\
\hline & Média & $\begin{array}{c}\text { Desvio- } \\
\text { padrão }\end{array}$ & Média & $\begin{array}{c}\text { Desvio- } \\
\text { padrão }\end{array}$ & Média & $\begin{array}{c}\text { Desvio- } \\
\text { padrão }\end{array}$ & Média & $\begin{array}{c}\text { Desvio- } \\
\text { padrão }\end{array}$ & Média & $\begin{array}{c}\text { Desvio- } \\
\text { padrão }\end{array}$ & Média & $\begin{array}{c}\text { Desvio- } \\
\text { padrão }\end{array}$ \\
\hline \multicolumn{13}{|l|}{ Altura do pasto $(10 \mathrm{~cm})$} \\
\hline Massa seca de forragem (kg/ha) & 853,3 & 41,6 & 1777,2 & 1132,0 & 978,7 & 110,9 & 898,7 & 449,2 & 1944,0 & 187,4 & 2306,7 & 940 \\
\hline Taxa de acúmulo (kg/ha) & - & - & 70,3 & 24,2 & 49,2 & 42,7 & 42,4 & 31,0 & 84,0 & 32,3 & 115,0 & 34,0 \\
\hline Relação lâmina/colmo+bainha & 8,09 & 1,25 & 1,43 & 0,38 & 1,24 & 0,41 & 1,24 & 0,27 & 1,00 & 0,21 & 0,09 & 0,08 \\
\hline \multicolumn{13}{|l|}{ Altura do pasto $(20 \mathrm{~cm})$} \\
\hline Massa seca de forragem & 826,7 & 306,2 & 2329,4 & 1219,3 & 2128,0 & 513,1 & 1949,3 & 528,8 & 3353,1 & 466,9 & 3464,0 & 170,3 \\
\hline Taxa de acúmulo & - & - & 49,8 & 11,2 & 44,4 & 27,7 & 56,8 & 23,8 & 78,7 & 26,4 & 12,3 & 0,0 \\
\hline Relação lâmina/colmo+bainha & 9,80 & 3,82 & 1,99 & 1,29 & 1,10 & 0,45 & 0,54 & 0,16 & 2,11 & 0,79 & 0,04 & 0,01 \\
\hline \multicolumn{13}{|l|}{ Altura do pasto $(30 \mathrm{~cm})$} \\
\hline Massa seca de forragem & 893,3 & 363,0 & 2655,2 & 1125,3 & 4381,3 & 1071,6 & 5250,0 & 1232,7 & 4456,0 & 657,2 & 4317,3 & 788,1 \\
\hline Taxa de acúmulo & - & - & 72,2 & 10,2 & 80,0 & 7,6 & 113,2 & 21,4 & 11,3 & 0,3 & 0,0 & 0,0 \\
\hline Relação lâmina/colmo+bainha & 7,78 & 3,11 & 1,50 & 0,26 & 0,64 & 0,08 & 0,29 & 0,09 & 2,35 & 0,73 & 0,06 & 0,02 \\
\hline \multicolumn{13}{|l|}{ Altura do pasto $(40 \mathrm{~cm})$} \\
\hline Massa seca de forragem & 1013,3 & 120,6 & 2788,5 & 729,1 & 5333,3 & 497,8 & 6232,0 & 198,1 & 4746,7 & 279,7 & 5349,3 & 1519,0 \\
\hline Taxa de acúmulo & - & - & 79,3 & 6,6 & 81,8 & 37,5 & 47,8 & 41,7 & 0,0 & 0,0 & 46,7 & 48,6 \\
\hline Relação lâmina/colmo+bainha & 3,69 & 2,95 & 1,27 & 0,13 & 0,43 & 0,02 & 0,25 & 0,04 & 1,70 & 0,22 & 0,03 & 0,01 \\
\hline
\end{tabular}

Tabela 4 - Características produtivas de pastos mistos de aveia e azevém manejados em quatro alturas

\begin{tabular}{|c|c|c|c|c|c|}
\hline & & & & & \\
\hline & & $10 \mathrm{~cm}$ & $20 \mathrm{~cm}$ & $30 \mathrm{~cm}$ & $40 \mathrm{~cm}$ \\
\hline Massa seca de forragem (kg/ha) & Média & $1710 d$ & $2580 c$ & $3430 b$ & $4060 \mathrm{a}$ \\
\hline & Erro-padrão & 25,5 & 17,2 & 129,7 & 108,5 \\
\hline Taxa de acúmulo(kg de MS/ha) & Média & $63,7 \mathrm{a}$ & $48,8 \mathrm{a}$ & $58,8 a$ & $51,9 a$ \\
\hline & Erro-padrão & 12,2 & 9,2 & 4,3 & 10,3 \\
\hline Acúmulo de forragem(kg de MS/ha) & Média & $9210 \mathrm{a}$ & $7270 \mathrm{a}$ & $8600 a$ & $7760 \mathrm{a}$ \\
\hline & Erro-padrão & 1592 & 1195 & 558 & 1364 \\
\hline Relação lâmina/colmo + bainha & Média & $0,66 a$ & $0,82 \mathrm{a}$ & $0,79 a$ & $0,58 \mathrm{a}$ \\
\hline & Erro-padrão & 0,09 & 0,18 & 0,18 & 0,05 \\
\hline
\end{tabular}

Médias com letras minúsculas, distintas na mesma coluna, diferem a $\mathrm{P}<0,10$. 
de avaliação foi bastante semelhante para todos os tratamentos. As diferenças começam a se pronunciar em setembro, quando a média das taxas de acúmulo verificada nos tratamentos 30 e $40 \mathrm{~cm}$ foi cerca de duas vezes maior que aquela das alturas 10 e $20 \mathrm{~cm}$. Porém, a drástica mudança de estrutura que ocorre entre meados de setembro e meados de outubro, decorrente da maior proporção de perfilhos florescidos, caracterizada pela acentuada redução da relação lâmina/colmo+bainha nas alturas de 30 e $40 \mathrm{~cm}$ (Tabela 3), fez com que as taxas de acúmulo no final do ciclo se invertessem. Como resultado, as taxas médias de acúmulo e o acúmulo total de forragem não diferiram entre alturas. Essas respostas já foram anteriormente observadas por Aguinaga et al. (2008), que utilizaram um protocolo experimental semelhante. Com relação à magnitude dos valores observados, tanto as taxas diárias de acúmulo quanto o acúmulo total de forragem foram superiores aos reportados por Soares et al. (2001) para pastos mistos de aveia e azevém (37 e 7014 kg de MS, respectivamente), a despeito do uso de níveis superiores de adubação nitrogenada. Já Roso et al. (1999) reportaram taxas de acúmulo médio para misturas de aveia e azevém semelhantes às registradas neste experimento.

Apesar de toda a variação em estrutura dos pastos descrita anteriormente e da escala temporal relativamente curta em que ocorreram, as mesmas compensações anteriormente descritas se verificaram, de certa forma, na estimação da massa seca de forragem por meio da altura, cujo modelo linear se ajustou $(\mathrm{P}<0,0001)$ com adequado poder de predição para a referida variável (Figura 2). O coeficiente de regressão indicou que para cada centímetro de altura no dossel correspondeu um incremento de aproximadamente $108 \mathrm{~kg}$ de MS/ha. Esse valor éintermediário em relação àquele reportado por Aguinaga et al. (2008), que observaram 86,3 kg de MS/cm de altura, e por Cassol (2003), de $130 \mathrm{~kg}$ de MS/cm de altura.

Em decorrência desses resultados é possível sugerir que a altura do pasto possa ser utilizada como uma ferramenta útil de manejo, pois, apesar de toda a variação intrínseca aos dados, ela demonstra que pode ser bem utilizada, tanto em modelos de predição quanto no estabelecimento de metas de estrutura do pasto com vistas à produção animal. Assim, Aguinaga et al. (2006) e Terra Lopes et al. (2008) argumentam que a altura de manejo para misturas de aveia e azevém deveria ser em torno de 20 a $25 \mathrm{~cm}$ de altura, quando elevados desempenhos por animal e por unidade de área seriam obtidos. No entanto, este experimento demonstrou que a média dos parâmetros pouco quer dizer em se tratando de pastagens anuais de inverno. Mesmo que a altura seja atingida, considerando a média do período de utilização, a variação e a dinâmica em torno dela são muito pronunciadas. No início do uso da pastagem, metas de altura mais elevadas favorecem o crescimento vegetal e a produção animal, como descrito por Terra Lopes et al. (2008). Porém, muito rapidamente a estrutura dos pastos de maior altura se degrada, e aqueles mantidos sob maiores intensidades de pastejo (alturas mais baixas) passam a ser os de melhor desempenho. Os resultados deste trabalho parecem indicar o início do mês de setembro como o momento no qual ocorrem alterações decisivas na estrutura desses tipos de pastagem. Isso daria margem à interpretação de que, mais do que se ter uma única meta de estrutura ao longo de todo o ciclo de utilização, provavelmente duas, pelo menos, deveriam ser as metas, e que se alterassem ao longo do tempo, procurando extrair o melhor da produtividade do pasto. Esse tipo de abordagem já se mostrou de elevado interesse para a definição de metas de manejo para outros tipos de pastagens (azevém-perene, Armstrong et al., 1995; pastagem nativa, Soares et al., 2005). Em sua concepção, a variação das metas reconhece o estabelecimento e o crescimento da heterogeneidade no pasto à medida que o animal exerce o pastejo, ainda que com maior ou menor grau de seletividade. Mais do que evitar a heterogeneidade no pasto, com prejuízo à seletividade animal, a sua manipulação ao longo do ciclo de utilização da pastagem se constituiria numa interessante pista de investigação para estudos futuros.

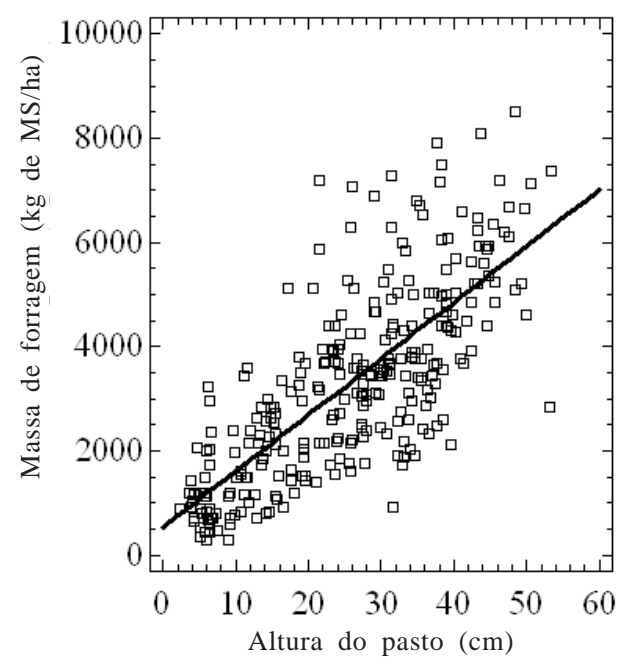

Figura 2 - Relação entre altura e massa seca de forragem de pastos mistos de aveia e azevém manejados em quatro alturas $\left(\mathrm{Y}=438,54+107,47 \mathrm{x} ; \mathrm{P}<0,0001 ; \mathrm{R}^{2}=67,67 \% ; \mathrm{n}=299\right.$; $\mathrm{CV}=30,34 \%)$. 


\section{Conclusões}

A massa seca de forragem do pasto pode ser estimada por meio de sua altura média. Quando o pasto é submetido a pastejo intenso, no início do período de utilização, a amplitude de distribuição das frequências de altura é pequena indicando menor heterogeneidade do pasto, ao contrário do que ocorre em menores intensidades de pastejo. Esse fenômeno se inverte à medida que o ciclo de utilização progride. A heterogeneidade rapidamente se instala com a presença do animal. A partir do mês de setembro, ocorrem fortes mudanças estruturais, que exigem no manejo do pasto, além da manutenção de metas de altura fixas, a utilização de alturas variáveis ao longo do período de utilização.

\section{Agradecimentos}

À Agropecuária Cerro Coroado, ao Conselho Nacional de Desenvolvimento Científico e Tecnológico (CNPq), à Coordenação de Aperfeiçoamento de Pessoal de Nível Superior (CAPES) e ao Programa de Iniciação Científica da UFRGS, pelo apoio. Aos professores Ibanor Anghinoni, César H. E. C. Poli e ao bolsista Caetano Pedroso Albuquerque, pelo auxílio.

\section{Referências}

ALMEIDA, E.X.; MARASCHIN, G.R.; HARTHMANN, O.E.L. et al. Oferta de forragem de capim-elefante anão "Mott" e o rendimento animal. Revista Brasileira de Zootecnia, v.29, p.1288-1295, 2000.

AguinagA, A.A.Q.; CARVAlho, P.C.F.; ANGHinOni, I. et al. Produção de novilhos superprecoces em pastagem de aveia e azevém submetida a diferentes alturas de manejo. Revista Brasileira de Zootecnia, v.35, p.1765-1773, 2006.

AGUiNAGA, A.A.Q.; CARVALHO, P.C.F.; ANGHINONI, I. et al. Componentes estruturais e produção de forragem de uma pastagem de aveia e azevém submetida a diferentes alturas de manejo. Revista Brasileira de Zootecnia, v.37, p.1523-1530, 2008.

ARMSTRONG, R.H.; ROBERTSON, E.; HUNTER, E.A. The effect of sward height and its direction of change on the herbage intake, diet selection and performance of weaned lambs grazing ryegrass swards. Grass and Forage Science, v.50, p.389-398, 1995.

BARTHRAM, G.T. Experimental techniques: the HFRO sward stick. In: ALCOCK, M.M. (Ed.) Biennial Report of the Hill Farming Research Organization. Midlothian: Hill Farming Research Organization, 1985. p.29-30.

BARTHRAM, G.T.; DUFF, E.I.; ELSTON, D.A. et al. Frequency distributions of sward height under sheep grazing. Grass and Forage Science, v.60, p.4-16, 2005.

BIRCHAN, J.S.; HODGSON, J. The influence of sward conditions on rate of herbage growth and senescence in mixed swards under continuous grazing management. Grass and Forage Science, v.38, p.323-331, 1983.
CARVALHO, P.C.F.; RIBEIRO FILHO, H.M.N.; POLI, C.H.E.C et al. Importância da estrutura da pastagem na ingestão e seleção de dietas de animais pelo animal em pastejo. In: MATTOS, W.R.S. (Org.) Produção animal na visão dos brasileiros. Piracicaba: Fundação de Estudos Agrários Luiz de Queiroz, 2001. p.853-871.

CASSOL, L.C. Relações solo-planta-animal num sistema de integração lavoura-pecuária em semeadura direta com calcário na superfície. 2003. 143f. Tese (Doutorado em Agronomia - Ciência do Solo) Departamento de Solos, Universidade Federal do Rio Grande do Sul, Porto Alegre.

EMPRESA BRASILEIRA DE PESQUISA AGROPECUÁRIA EMBRAPA. Centro Nacional de Pesquisa de Solos. Sistema Brasileiro de Classificação de Solos. Brasília: EMBRAPA. Rio de Janeiro, 1999. 412p.

FISHER, D.S. Defining the experimental unit in grazing trials. Proceedings of the American Society of Animal Science, p.1-5, 1999.

GARCIA, F.; CARRÈRE, P.; SOUSSANA, J.F. et al. Characterization by fractal analysis of foraging paths of ewes grazing heterogeneous swards. Applied Animal Behaviour Science, v.93, p.19-37, 2005.

GIBB, M.J.; RIDOUT, M.S. The fitting of frequency distributions to height measurements on grazed swards. Grass and Forage Science, v.41, p.247-249, 1986.

GIBB, M.J.; RIDOUT, M.S. Application of double normal frequency distributions fitted to measurements of sward height. Grass and Forage Science, v.43, p.131-136, 1988.

MORAES, A.; MOOJEN, E.L.; MARASCHIN, G.E. Comparação de métodos de taxas de crescimento em uma pastagem submetida a diferentes pressões de pastejo. In: REUNIÃO ANUAL DA SOCIEDADE BRASILEIRA DE ZOOTECNIA, 27., 1990, Campinas. Anais... Campinas: Sociedade Brasileira de Zootecnia, 1990. p.332.

MOTT, G.O.; LUCAS H.L. The design, conduct, and interpretation of grazing trials on cultivated and improved pastures. In: International grassland congress, 6., 1952, Pensylvania. Proceedings... Pensylvania: State College Press, 1952. p.1380-1385.

PONTES, L.S.; CARVALHO, P.C.F.; NABINGER, C. et al. Fluxo de biomassa em pastagem de azevém anual (Lolium multiflorum Lam.) manejada em diferentes alturas. Revista Brasileira de Zootecnia, v.33, p.529-537, 2004.

QUADROS, F.L.F. Produtividade animal a pasto: manejo e utilização de forrageiras de inverno em terras altas, integrando lavoura do seco e pecuária. In: CICLO DE PALESTRAS EM PRODUÇÃO E MANEJO DE BOVINOS DE CORTE, 1999, Canoas. Anais... Canoas: ULBRA, 1999. p.91-100.

ROCHA, G.M.; MONTAGNER, D.B.; SANTOS, D.T. et al. Parâmetros produtivos de uma pastagem temperada submetida a alternativas de utilização. Revista Brasileira de Zootecnia, v.33, p.1386-1395, 2004.

ROSO, C.; RESTLE, J.; SOARES, A.B. Produção e qualidade de forragem da mistura de gramíneas anuais de estação fria sob pastejo contínuo. Revista Brasileira de Zootecnia, v.28, p.459-467, 1999.

SANDERS, I.; TOPP, C.F.E.; SWAIN, D. et al. Modelling seasonal changes in spatial heterogeneity of sward height in grass-clover and grass only swards. In: BGS RESEARCH CONFERENCE, 7., 2003, Aberyswyth. Proceedings... Aberyswyth, 2003. p.41-42.

SILVA, S.C.; CARVALHO, P.C.F. Foraging behaviour and herbage intake in the favourable tropics/subtropics. In: McGILLOWAY, D.A. (Ed.). Grassland: a global resource. Wageningen, 2005. p.81-96.

SOARES, A.B.; RESTLE, J.; ROSO, C. et al. Dinâmica, qualidade, produção e custo de produção de forragem da mistura de aveia preta e azevém anual adubada com diferentes fontes de nitrogênio. Ciência Rural, v.31, p.117-122, 2001. 
SOARES, A.B.; CARVALHO, P.C.F.; NABINGER, C. et al. Produção animal e de forragem em pastagem nativa submetida a distintas ofertas de forragem. Ciência Rural, v.35, p.1148-1154, 2005.

SOLLENBERGER, L.E.; MOORE, J.E.; ALLEN, V.G. et al. Reporting forage allowance in grazing experiments. Crop Science, v.45, p.896-900, 2005.
STATISTICAL ANALYSES SYSTEM - SAS. SAS/STAT user's guide: Statistics. 4.ed. Version 6. Cary: 2001, v.2. 943p.

TERRA LOPES, M.; CARVALHO, P.C.F.; ANGHINONI, I. et al. Sistema de integração lavoura-pecuária: desempenho e qualidade da carcaça de novilhos superprecoces terminados em pastagem de aveia e azevém manejada sob diferentes alturas. Ciência Rural, v.38, p.178-184, 2008. 